\title{
Chemical Cancer Immunotherapy
}

National Cancer Institute

\section{Source}

National Cancer Institute. Chemical Cancer Immunotherapy. NCI Thesaurus. Code C15975.

Chemical Cancer Immunotherapy is the use of chemical substances to alter the interaction between the host's immune defenses and cancer cells to boost, direct, or restore the body's ability to fight cancer. 